\title{
Trabalhonecessário
}

Issn: 1808 - 799X

ano 14, número $24-2016$

\section{DE QUE É FEITO UM IMPÉRIO? \\ trabalho forçado nas colónias portuguesas}

\author{
Raquel Varela \\ João Carlos Louçã ${ }^{1}$
}

\begin{abstract}
Portugal was the empire that most used various forms of forced labour in the most systematic way and for the longest time. Widely denounced in the press and by international agencies, forced labour brought with it all the ailments of the society of which it was part: poverty, non-existence of social mobility, family break-ups, mere subsistence agriculture, extreme income inequality and a racist political police.
\end{abstract}

Keywords: portuguese colonies, forced labour, racism

\section{Resumo}

Portugal foi o império que mais utilizou, através de várias formas, o trabalho forçado, sistematicamente e por mais tempo. Realidade denunciada pela imprensa e agências internacionais, o trabalho forçado inseriu-se nos pilares da sociedade de que fazia parte: pobreza, inexistência de mobilidade social, separação familiar, agricultura de subsistência, extrema desigualdade de rendimentos e uma polícia política racista.

Palavras-chave: colónias portuguesas, trabalho forçado, racismo

1 Raquel Varela é investigadora do Instituto de História Contemporânea da Universidade Nova de Lisboa, Professora Convidada na UFF Brasil e membro honorário do International Institute of Social History. João Carlos Louçã é investigador do Instituto de História Contemporânea da Universidade Nova de Lisboa, doutorando em Antropologia pela mesma Universidade. 


\section{Trabalhonecessário}

Issn: 1808 - 799X

ano 14, número $24-2016$

Nos países do sul da Europa sentimos hoje com intensidade várias formas de desregulamentação da relação capital/trabalho num caminho de erosão dos direitos sociais associados ao trabalho.

Nesse caminho em que nos encontramos, parece que 0 trabalho forçado e a escravatura, voltaram a entrar no léxico comum para definir novas tendências das relações contratuais. É o caso evidente da continuidade de redes de trabalho forçado na agricultura, no trabalho sexual ou na construção civil, que aproveitando a clandestinidade (também ela forçada) de muitos imigrantes, ganha terreno como uma dolorosa realidade social. Mas será também o caso de todos os trabalhos oferecidos sem salário - estágios não remunerados, trabalhos para o curriculum, situações de ambiguidade contratual em que o trabalho das pessoas não é formalmente reconhecido como tal e por esse motivo também não é remunerado. Em Portugal, o Estado consegue ser o principal agente deste tipo de contratos.

Por outro lado, a intensificação dos ritmos, dos horários e das formas de trabalhar, mesmo quando há uma relação contratual que implique um salário, é entendida por muitos como uma espécie de regresso a um tempo de escravidão. Nunca como hoje, o trabalho esteve tão distante da satisfação e realização humanas. Nunca como hoje, a ameaça do regresso a formas do passado pré-capitalista nas relações laborais, ilustrou de forma tão absoluta os caminhos possíveis da continuidade da acumulação capitalista. $O$ capital sem rosto do século XXI, parece resgatar com sucesso, para a Europa do Sul, formas de trabalho forçado, que só uma perspetiva demasiado centrada na chamada "cultura ocidental", poderia afirmar que se trataria de uma realidade ultrapassada.

Em Portugal a economia é grandemente devedora do trabalho escravo das colónias e após a abolição jurídica da escravatura em 1878, da sua continuidade através do trabalho forçado. Num processo simultâneo de expropriação dos meios de produção africanos tradicionais, Portugal foi o império que mais usou, de forma sistemática e por mais tempo, várias formas de trabalho forçado. Este sobrevive até 1974, quando uma revolução na metrópole converge com os movimentos africanos de libertação nacional, determinando o fim de um império que nunca conseguiu acompanhar os ventos da 


\section{Trabalhonecessário}

Issn: 1808 - 799X

ano 14, número $24-2016$

industrialização e da constituição de mercados onde os produtores pudessem vender a sua força de trabalho.

Esta sobrevivência do trabalho forçado até 1974 é controversa para alguns historiadores. Como Jeremy Ball que considera que a partir do final dos anos 60 e na década de 70 , o regime português mudou a sua política africana e deu os passos necessários para que este fosse definitivamente banido (Ball, 2015). Suportando esta afirmação na análise dos textos diplomáticos, nas inspeções internacionais e na própria retórica do regime, ao contrário de Ball, preferimos aqui considerar que para além das aparências e do discurso do regime sobre si próprio, a realidade da guerra e de um sistema repressivo, não podia dispensar o trabalho compelido dos africanos. E não o fez até ao momento da sua desagregação final.

A história deste regime de trabalho é a história da exploração colonial e da acumulação de riquezas através de uma força de trabalho violentada e forçada. Forma de continuidade do regime esclavagista e do racismo como ideologia de supremacia branca europeia, a história do trabalho forçado dos africanos nas colónias portuguesas é a história de um império simultaneamente em decadência e em afirmação nacionalista face a um mundo em mudança. Essa mudança torna-se particularmente visível no período após a segunda guerra mundial, quando os ventos da libertação empurraram a situação de muitas colónias africanas para formas de autonomia percursoras da independência que muitos territórios conquistaram na década seguinte. Portugal mantevese à margem desse processo, sem qualquer iniciativa que considerasse as organizações de nacionalistas africanos interlocutoras, sem qualquer reconfiguração do seu espaço colonial, mantendo um discurso e práticas que subjugavam os povos africanos ao seu domínio e aos seus interesses económicos.

Não por acaso, o acontecimento considerado como o momento inaugural da luta de libertação nacional, ou ainda o que Dalila Mateus considerou ser o ensaio geral da guerra colonial, foi no norte de Angola, em janeiro de 1961, uma greve de trabalhadores do algodão na baixa de Cassange. Na repressão consequente, o exército português utiliza napalm no bombardeamento das populações locais provocando a morte de 10 a 20 mil pessoas, arrasando aldeias inteiras (Mateus, 2013).

Neste conflito, as populações indígenas eram obrigadas a cultivar algodão que 


\section{Trabalhonecessário}

Issn: 1808 - 799X

ano 14, número $24-2016$

tinham de vender à empresa Cotonang, de capitais portugueses e belgas. Esta empresa que detinha o monopólio do cultivo e da comercialização do algodão, vendia as sementes aos agricultores e comprava-Ihes a produção por preços muito inferiores aos de mercado. O resultado era a destruição das culturas de subsistência, substituídas pela monocultura do algodão, deixando os agricultores africanos na dependência da Cotonang e dos resultados de uma colheita que, em anos maus, condenava populações inteiras à fome. Este acontecimento, marcou o início da luta armada do MPLA e deu projeção internacional a uma política colonial brutal e desfasada do seu tempo.

Marx no Capital, olhou para as relações coloniais do seu tempo para ilustrar o processo histórico da separação do produtor dos meios de produção, característico do capitalismo em todas as latitudes onde este se afirmou. A acumulação primitiva de capital, conceito desenvolvido por Adam Smith, é designada por Marx como a raiz do processo de afirmação do capitalismo e a expropriação do produtor agrícola do solo o momento inicial da acumulação primitiva numa espécie de pecado original na economia política. A exploração de África pelo colonialismo europeu, pode bem ilustrar a afirmação de Marx de que esta "expropriação está inscrita nos anais da humanidade com letras de sangue e fogo" (Marx, p.669) Mas ao contrário das Américas, onde milhões de europeus se deslocaram e constituíram, a par com os africanos escravizados, a mão-de-obra necessária aos processos de modernização capitalista, em África a ocupação europeia foi muito débil. Em Angola, em 1955, para mais de 4 milhões de africanos havia menos de 80 mil europeus. Em 1925 eram 25 mil e em 1911 apenas 13 mil (Davidson, 1972, p. 121).

$\mathrm{Na}$ sua fase final, o regime do Estado Novo, reproduzia uma ideologia de paternalismo protetor face às populações nativas, onde se enquadrava naturalmente a missão civilizadora cristã através do trabalho e da assimilação. Sarmento Rodrigues, Contra-Almirante e Governador-Geral de Moçambique em 1962 resumia assim a presença portuguesa em África:

Desde os primeiros dias, não repelimos os indígenas. Tratámo-los sempre com humanidade e, em frequentes casos, fizemo-los ingressar na nossa família. Ao mesmo tempo, civilizando-os à nossa maneira, demos-lhes os nossos costumes e as nossas leis. Isto é, por simples generosidade natural quisemos fazer deles nossos iguais. Hoje, entre nós, no Ultramar em África, só existem duas classes de indivíduos portugueses: civilizados e indígenas. 


\section{Trabalhonecessário \\ Issn: 1808 - 799X \\ ano 14, número $24-2016$}

Os segundos pelos seus costumes, primitivos, são protegidos. Dos civilizados, não curamos saber se são pretos, brancos ou mestiços: todos iguais, todos civilizados. Nada mais cristão, mais humano, mais generoso. E pura assimilação.(Rodrigues, 1962, p.119)

$\mathrm{Na}$ verdade as políticas ensaiadas, resultaram num flagrante fracasso. $\mathrm{Na}$ generalidade das colónias, os africanos civilizados e teoricamente iguais perante a lei aos colonos brancos, eram em número bastante reduzido e predominavam os indígenas, considerados primitivos e submetidos a essa missão civilizadora que Sarmento Rodrigues refere. Mesmo assim, a importância dos estudantes africanos que estudaram na metrópole e que aí se organizaram em diferentes grupos políticos de resistência integrando os Movimentos de Libertação Nacional, confirma até que ponto as políticas de assimilação e os discursos oficiais foram um paradigma do fracasso da colonização portuguesa.

As estimativas mais conservadoras indicam que em Angola mais de 2 milhões de pessoas teriam sido exportadas para as Américas entre meados do século XVII e XIX na chamada rota do Reino do Congo. Esse Atlântico Negro, na definição de Paul Gilroy (2001), responsável por contraculturas da modernidade forjadas num processo onde o cativeiro e a resistência são o elemento central, contribuiu decisivamente para a acumulação de riquezas do mundo ocidental e abrangeu quase todas as sociedades da África Central. O controlo da mão-de-obra africana seria a chave principal de riqueza e poder, quer para os habitantes da colónia portuguesa, quer para os chefes políticos africanos. Esvaziou territórios e redefiniu relações sociais e políticas entre grupos vizinhos. Fez emergir estados africanos poderosos que se afirmavam na dependência deste tráfico transatlântico (Dias, 2000).

Particularmente em Angola, o regime colonial ensaiou a tentativa de ali reproduzir um novo Brasil com o desenvolvimento das culturas do café, algodão e as grandes plantações de açúcar, logo desde o início do século XX. A falta de capital para o investimento, o clima e os solos tornaram este empreendimento uma miragem nunca alcançada. Verdadeiramente, só a indústria de aguardente floresceu, com a finalidade do comércio com as sociedades africanas. Até muito tarde, já no século $X X$ e com muito mais intensidade a partir do início da guerra colonial, a colonização dos territórios ultramarinos de África, foi, em grande medida, resultado das circunstância de um império 


\section{Trabalhonecessário}

Issn: 1808 - 799X

ano 14, número $24-2016$

frágil e pouco capaz de exportar colonos, militarmente acossado e sem capacidade económica para desenvolver uma política extensiva de controlo e dominação dos territórios coloniais. Praças fortes no litoral que serviam para o comércio com as populações do interior e para controlarem as vias marítimas essenciais, assim pode ser resumida a colonização portuguesa em África até muito tarde. Processo invertido na segunda metade do século XX, com as necessidades da guerra e de controlo maior do território, com o incremento de fluxos entre a metrópole e as colónias: mercadorias, pessoas, materiais militares, e ainda de projeções simbólicas onde a grandeza e capacidade do império se encontravam em jogo. País pequeno e pobre na Europa, só a sua dimensão colonial justificava o discurso de grandeza que o Estado Novo reproduzia e onde assentava as suas bases ideológicas. Por outro lado, as necessidades militares faziam da migração do continente, uma necessidade premente de uma colonização tardia e que transformou a vida de muitos milhares de pessoas que em Portugal eram trabalhadores sem nada para além da sua força de trabalho e nas colónias tinham o estatuto privilegiado dos brancos, terras e funções atribuídas pela administração.

\section{Pressão internacional}

O final legal da escravatura, período compreendido entre 1858 e 1878, viu simultaneamente aumentar o número de escravos nos núcleos coloniais em $30 \%$. Já depois de 1878, a produção de cacau nas ilhas de São Tomé e Príncipe, fez mergulhar todo o território angolano num novo surto de tráfico. Este tráfico em concreto, foi responsável por uma iniciativa de boicote de William Cadbury, fabricante britânico de chocolate, que concluiu em 1909 que os donos de plantações e o governo português eram responsáveis pela continuidade da escravatura nestas ilhas. Mesmo quando a palavra "escravatura" era afastada do léxico da administração colonial e a sua realidade sempre negada, os trabalhadores contratados ou os regimes de angariação de voluntários, eram formas de forçar os africanos ao trabalho, na maior parte da vezes sem mais regalias ou condições do que na escravatura.

Quakers, a família Cadbury inscrevia-se na tradição protestante que já desde o final do século XVIII tinha combatido a escravatura e não podia agora beneficiar dela 


\section{Trabalhonecessário}

Issn: 1808 - 799X

ano 14, número $24-2016$

mesmo que sob formas que escondiam a realidade do trabalho compelido. Face às denúncias internacionais, Cadbury vem a Lisboa em 1903 e recebe garantias das autoridades de que se prepara legislação para estabelecer um salário para os trabalhadores das roças e que estes pudessem voltar às suas terras de origem, depois de terminado o contrato. Dois anos depois, o empresário envia a São Tomé um representante, Joseph Burtt, para esclarecer as condições de trabalho nas roças de cacau da ilha. Esta delegação inclui um jornalista, Henry Nevinson, que escreve um artigo no Harper's Magzine com o título O comércio de escravos hoje: as ilhas da condenação. ${ }^{2}$ Nesse artigo, o jornalista afirma que o regime dos trabalhadores nas roças de São Tomé é igual ao dos escravos uma vez que estes nunca voltam a casa e que os contratos só terminam com a sua morte. A legislação prometida era uma manobra de diversão e uma forma de camuflar uma realidade contestada internacionalmente, uma vez que as condições de trabalho não diferiam daquelas da escravatura. No relato deste jornalista, a evidência de que a diplomacia do Estado português trabalhou desde muito cedo na contra-informação sobre as colónias e o seu regime opressivo. Contrariando os relatos independentes de todos os observadores no terreno, o regime ditatorial português foi sempre capaz de produzir uma aparência de modernidade e de abertura, mesmo e sobretudo quando esta servia os interesses da continuidade da exploração da força de trabalho africana, sem grandes alterações. Por isso a legislação e os documentos legais da administração colonial, refletiam mais uma realidade de ocultação e camuflagem do que a situação real das condições de trabalho nas plantações.

Quando em 1909 o fabricante britânico de chocolate encontra alternativa ao fornecimento de cacau na Costa do Ouro, anuncia o boicote que se manterá em vigor até 1916.

Em 1899, o Regulamento do Trabalho Indígena das Colónias estabelecia o trabalho forçado nas seguintes categorias: "compelido", "correcional", "em obras de interesse público" e "contratado". A par com estas modalidades de trabalho forçado, havia ainda o trabalho "voluntário". Paradoxalmente, este último era geralmente pago abaixo dos salários do trabalho forçado nomeadamente na modalidade de "contratado", tendo

2 Citado por Emilia Caetano em "A segunda escravatura”, Visão/História, março 2016. 


\section{Trabalhonecessário}

Issn: 1808 - 799X

ano 14, número $24-2016$

como vantagem apenas ser realizado na região de origem dos trabalhadores. No mesmo regulamento afirmava-se que os indígenas das colónias portuguesas estavam sujeitos à obrigação moral e legal de procurar através do trabalho os meios necessários para subsistir e melhorar a sua condição social.

A partir de 1907 é instaurado o "imposto de cubata", substituído em 1919 por um imposto indígena de capitação. Tal como noutras colónias europeias, este imposto empurrava os africanos para a dependência de uma economia monetária, vendo-se assim obrigados a trabalhar fora das culturas tradicionais que até então Ihes tinham garantido a subsistência. Na letra da lei, a este imposto indígena, correspondia uma missão civilizadora, ao fomentar o trabalho e garantir a pacificação e submissão dos africanos. É este imposto, repleto de intenções morais, que impele os africanos a procurarem trabalho com remuneração monetária. A primeira modalidade deste trabalho foi o transporte, em que os homens substituíam animais de carga. Depois foi o trabalho agrícola obrigatório em que a troco de salários irrisórios, os homens deixavam as suas aldeias para ir trabalhar no algodão, no chá, no arroz. Depois o trabalho nas minas do Transval, no caso de Moçambique, do cacau em São Tomé e Príncipe, de todos os trabalhos domésticos em todas as colónias.

O Código de Trabalho Indígena de 1928 afirmava que não se podia permitir aos indígenas nenhuma forma de trabalho compelido para fins particulares. No entanto, continuava a sublinhar o dever moral de trabalhar. Este diploma que passou a constituir a coluna vertebral do sistema de trabalho nas colónias, inaugurou o sistema de contratos que só na aparência eram voluntários. Por outro lado, qualquer administrador local poderia considerar de interesse público o trabalho de africanos em empreendimentos particulares. Em 1962, publica-se o Código de Trabalho Rural. Este documento permitia ao regime defender-se das instâncias internacionais - ONU e OIT - e da opinião pública internacional, ao declarar que a trabalho igual deveria corresponder trabalho igual. Mas tratava-se da maquilhagem de um sistema que não procurava seriamente reformular-se. Ao fixar a retribuição salarial através de convénios coletivos, numa realidade sem qualquer organização sindical, os trabalhadores africanos veriam os seus salários serem determinados por circulares clandestinas e muitas vezes sem serem publicadas nos boletins oficiais. 


\section{Trabalhonecessário}

Issn: 1808 - 799X

ano 14, número $24-2016$

Sobre a revisão constitucional de 1951 e a produção legislativa que the esteve associada, Adriano Moreira, que foi ministro do Ultramar entre 1961-63, referindo-se à substituição do termo "colonial" por "ultramar" na demonstração da vontade legislativa de acompanhar a evolução da terminologia usada internacionalmente, afirma que esta "teve na base mais a preocupação de tomar uma atitude perante as tendências internacionais do que exprimir um novo sentido da política consagrada nos textos". ${ }^{3}$

Este caráter ardiloso de maquilhar os documentos de uma sistema de exploração com base no trabalho forçado, deu os seus frutos diplomáticos, mas não resistiu ao inúmeros relatos que davam conta de uma realidade bem diferente daquela ventilada pelas autoridades portuguesas nas instâncias internacionais.

Por volta de 1935, Orlando Ribeiro, pai da geografia portuguesa e observador atento dos fenómenos sociais, em viagem por Angola, admirava-se por encontrar um conjunto de contratados, amarrados com cordas uns aos outros e guardados por dois guardas armados, mais de 50 anos depois da abolição da escravatura. "Fotografámos e filmámos tão degradante espetáculo e inquirimos aos guardas porque vinha aquela gente amarrada, que crime ou delito havia praticado. 'São vadios que na terra deles não querem trabalhar'" (Ribeiro, 1981, p. 162). Tal como na metrópole onde as leis repressivas sobre a vagabundagem eram aplicadas para disciplinar grupos sociais potencialmente subversivos, em África elas eram impostas aos africanos indiscriminadamente tendo por consequência a garantia do seu trabalho por custos irrisórios.

Em fevereiro de 1955 um anúncio no Diário de Luanda garantia "pessoal legalizado a mil escudos a cabeça", exemplo de venda da força de trabalho que não oferece aos africanos opção para o seu destino.

Mesmo a suposta utilização destas formas de trabalho compulsivo, que desde 1928 só poderia ser utilizado em trabalhos públicos, era imposta e transacionada pelos chefes de posto (os responsáveis locais pela administração colonial) para fins particulares numa preenchida rede de cumplicidades e subornos. Inspetor colonial em 1947, Henrique Galvão, divulga em sessão parlamentar fechada as suas conclusões:

o governo converteu-se no principal recrutador e distribuidor de mão-deobra nativa, a tal ponto que os colonos requisitam por escrito à Repartição

3 Citado por Rui M. Pereira , 2005 


\section{Trabalhonecessário}

Issn: 1808 - 799X

ano 14, número $24-2016$

de Assuntos Indígenas, os 'fornecimentos' de mão-de-obra sem qualquer pudor (...) Só os mortos estão realmente isentos de trabalho forçado (Anderson, 1966, p.51-52).

Galvão conclui que em muitos casos o regime de trabalho forçado criava uma situação pior que a da escravatura. Apesar da veemência da condenação, este relatório não teve consequências diretas na política de administração dos territórios ultramarinos, sendo fonte citada por muitas das investigações posteriores que se debruçaram sobre a complexidade desta teia de relações que impunham um regime de trabalho aos africanos em benefício dos colonos europeus e da administração colonial.

Na Guiné portuguesa por exemplo, é de salientar a utilização de trabalho intensivo de africanos na construção de estradas. Sem outros investimentos significativos, a rede de comunicações custou à população guineense mais de $10 \%$ de emigração até meados dos anos 30 e, ao contrário de Angola, na Guiné as populações nativas mantiveram o controlo sobre a produção de culturas de subsistência. Ao mesmo tempo, em Moçambique, a manutenção de estradas impressionava os viajantes europeus que observavam que era realizada por mulheres e crianças com instrumentos rudimentares e debaixo da coação armada das autoridades coloniais. Realidade mais gritante ao sul do território, onde se recrutava indígenas para trabalharem nas minas sul-africanas de ouro. Perry Anderson, em 1966, calculava que 100 mil trabalhadores de Moçambique eram fornecidos anualmente às minas da África do Sul. Implementado em 1909, este contrato renovado sucessivamente garantiu que uma parte significativa do trânsito de mercadorias para Johannesburg passasse pelo porto de Lourenço Marques ${ }^{4}$. Além de receber 150 escudos por cada trabalhador, o governo fica ainda com metade do salário, pago no final do contrato. Pago em ouro, esta metade do salário seria entregue ao trabalhador na desvalorizada moeda colonial.

Marcelo Caetano, que veria a suceder a Salazar, calculou o número de moçambicanos a trabalhar fora da província em cerca de 500 mil, no ano de 1954 . No mesmo ano, as Nações Unidas, estimaram também em 500 mil pessoas os angolanos a viver fora do território. No caso do sul de Moçambique, esta deslocação representaria

4 Lourenço Marques, explorador e comerciante português do século XVI é o nome colonial da capital moçambicana, hoje Maputo. 


\section{Trabalhonecessário}

Issn: 1808 - 799X

ano 14, número $24-2016$

mais de dois terços da força de trabalho masculina. Não só para as minas do Transval, mas também os deslocados para o trabalho nas plantações de cacau em São Tomé e Príncipe ou para o algodão da Rodésia do Sul.

\section{Aptidão para trabalho e as Missões Antropológicas}

Desde os anos 20 do século XX, que a Antropologia portuguesa encontrou protagonistas destacados na Escola do Porto que, em associação com a Universidade e o Museu de História Natural da cidade, desenvolveram a relação estreita da disciplina com a questão colonial. Na sua vertente largamente predominante, pelo menos até aos anos 40, a Antropologia era assunto de médicos e biólogos que procuravam nos estudos antropométricos das populações nativas, a sua aptidão para 0 trabalho $e$ as características físicas que suportavam os conceitos de raça e racialismo em voga na época. António Mendes Correia, professor catedrático, doutorado em antropologia física, homem do regime que chegou a ser Presidente da Câmara do Porto e da Sociedade Portuguesa de Geografia, dirigiu durante largo período a Junta das Missões Geográficas e de Investigações Coloniais (JMGIC), organismo na dependência do Ministério das Colónias, criado em janeiro de 1936. A JMGIC coordenou o trabalho das missões de investigação realizadas em Moçambique, na Guiné, em Angola, Cabo Verde, São Tomé e Príncipe e Timor, entre 1937 e 1956.

Em 1934, no I Congresso Nacional de Antropologia Colonial, realizado no Porto e em paralelo com a Exposição Colonial em que foi exibido um espólio considerável da investigação até então produzida sobre características físicas, serológicas e psicológicas das populações coloniais, a disciplina afirmava-se na utilidade do conhecimento sobre estas populações e, em particular "em prol de uma colonização mais racional e de uma revalorização da mão-de-obra indígena" (Pereira, 2005, p. 216).

Rui Pereira também analisa cada um dos relatórios das missões:

Nos vinte e três anos de ação das Missões Antropológicas em Moçambique, entre 1936 e 1959, foram publicados, em resultado e no quadro daquelas missões, 44 trabalhos, dos quais apenas 14 revelam do desígnios da Etnografia. Prosperavam os estudos de antropometria, sobretudo aqueles que diziam respeito ao aproveitamento da força de trabalho e cujos objetivos são facilmente descortináveis" (Pereira, 2005, p. 


\section{Trabalhonecessário}

Issn: 1808 - 799X

ano 14, número $24-2016$

212).

O regime, nas suas componentes académica e científica, olhava para as colónias africanas como um campo imenso de análise e conhecimento, com o intuito de incrementar as formas de exploração laboral e de adequar estratégias de dominação sobre as populações indígenas. O conhecimento antropológico teria assim uma utilidade dupla, a de dar a conhecer a supremacia racial justificando ao mesmo tempo o colonialismo, e a de melhor explorar a força de trabalho através do conhecimento das populações fornecedoras da mão-de-obra.

Medes Correia, feroz opositor da mestiçagem que considerava a "dissolução do Portugal multisecular" (Pereira, 2005, p. 217), via-se obrigado a defender a suposta pureza racial portuguesa contra as teorias pangermanistas da higiene racial e que argumentavam com a influência genética africana sobre a população portuguesa. As teorias da supremacia inata e do racismo a desdobrarem-se entre as falácias da construção artificiosa em há sempre uma raça superior a todas as outras e onde as identidades nacionais tão recentes e instáveis no caso de grande parte da Europa, eram afirmadas em termos de raça. A divergência insanável de Mendes Correia nesta corrente fundamental da antropobiologia era posta em prática nas concepções que desenvolveu e que enformaram o espírito das missões de investigação que dirigiu, mas, ao mesmo tempo, recorrendo ao seu quadro ideológico e conceptual: o racismo e as teorias de supremacia intelectual branca. Já na segunda metade do século e ao mesmo tempo que na Europa a Antropologia Física perdia fôlego enquanto ciência que abrangia a Etnologia e a Etnografia, Mendes Correia mantinha-se à frente da Escola do Porto. Continuaria a ser o representante nacional da disciplina, mesmo em congressos internacionais onde a vertente cultural e a Etnologia em particular se autonomizavam. Jorge Dias, primeiro vulto dessa viragem disciplinar em Portugal e que também produziu informação etnológica sobre as populações das colónias africanas, reconhecia em Mendes Correia um percursor com a capacidade para integrar os estudos culturais nas políticas de investigação que dirigiu.

\section{Trabalho forçado ou a escravatura moderna}




\section{Trabalhonecessário}

Issn: 1808 - 799X

ano 14, número $24-2016$

Anderson é peremptório na classificação do que designou como "ultracolonialismo": "A opressão humana envolvida no trabalho forçado português é de uma brutalidade e intensidade que não têm paralelo em qualquer outra parte do continente. É o absoluto, o zénite da miséria africana" (Anderson, 1966, p. 50). Calcula haver mais emigrados africanos, legais ou ilegais, de Angola e Moçambique, do que de todo o resto de África.

Basil Davidson, que dedicou a Angola a atenção de uma vida, chamou ao trabalho forçado modern slavery e apesar de admitir que existiu de uma forma ou de outra em todas as colónias africanas, é em Angola que garante a economia da colónia numa espécie de reminiscência do imperialismo pré-industrial do passado. Davidson traz à luz o papel cúmplice e duplamente ambíguo das autoridades britânicas com um regime de trabalho que, mesmo provocando fortes críticas, beneficiava os seus interesses económicos (Davidson, 1955). Império sob tutela, Portugal colonial guardava para si a execução de políticas atrasadas de angariação de mão-de-obra, ao mesmo tempo que os dividendos dessa exploração eram repartidos generosamente pelas potências económicas europeias que se livravam das suas colónias sem deixar de tentar os seus negócios e hegemonia comercial em todo o conjunto dos territórios africanos. A presença de capital estrangeiro em Angola era calculada pelo Plano de Fomento de 1968/77 em cerca de $44 \%$ da economia. Essa presença ganhava corpo na indústria extrativa, em infraestrutras e na agricultura, na energia e na banca, no comércio, na importação/exportação. A diplomacia económica garantia o apoio necessário ao regime português e à guerra colonial, para proteção destes investimentos.

"Tributo em espécie cobrado pelo vencedor ao povos dominados", assim foi definido o trabalho forçado (Havik, 2006, p. 243). E Portugal, império frágil que fez da metrópole passagem da riqueza com origem na espoliação colonial, dominava na sua enorme fraqueza. Paradoxalmente, é a economia da guerra a partir da década de 60 do século $\mathrm{XX}$, que fornece algum investimento aos territórios coloniais e que começa a ver nascer algum mercado interno nas colónias. Invertendo a política oficial de Salazar de baixo investimento e de manter as colónias em situação de absoluta dependência para evitar perspectivas autonómicas como tinha acontecido no Brasil. Ao mesmo tempo que na metrópole a miséria se espalhava nos campos sem significativa contrapartida industrial, 


\section{Trabalhonecessário}

Issn: 1808 - 799X

ano 14, número $24-2016$

levando gerações inteiras a procurarem condições de vida na imigração, sobretudo para França, o regime ensaiava em África um último ato do delírio imperial.

"Todos para Angola, rapidamente e em força" - o grito estéril de Salazar condenou muitos milhares de jovens, populações de muitas regiões africanas, gerações de pessoas que ainda hoje tentam cicatrizar as feridas deixadas pela barbárie da guerra ${ }^{5}$ Mas ao mesmo tempo terá contribuído para o momento libertador na madrugada de abril de 1974. Esse dia inicial, inteiro e limpo, na poesia de Sophia de Mello Breyner, tornado possível pela resistência africana e pelo seu contágio ao exército ocupante, foi também o último dia do trabalho forçado como sistema de dominação colonial.

\section{REFERÊNCIAS}

ANDERSON, Perry. Portugal e o Fim do Ultracolonialismo. Editora Civilização Brasileira, Rio de Janeiro 1966

BALL, Jeremy. "Colonial Labor in Twentieth-Century Angola" in History Compass 3 (2005) AF 168, 1-9

DAVIDSON, Basil. The African Awakening. Jonathan Cape, London, 1955

DAVIDSON, Basil. L'angola - au coeur des tempétes. François Maspero, Paris, 1972.

DIAS, Jill. "Relações Portuguesas com as Sociedades Africanas em Angola no Século XIX" in O Império Africano - séculos XIX e XX (coord. Valentim Alexandre). Colibri, Lisboa, 2000

GILROY, Paul. O Atlântico Negro - modernidade e dupla consciência. Editora 34, Rio de Janeiro, 2001

HAVICK, Philip J.. "Estradas sem fim: o trabalho forçado e a política indígena; na Guiné (1915-1945)" in Trabalho Forçado Africano - experiências coloniais comparadas (coord. Centro de Estudos Africanos da Universidade do Porto). Campo das Letras, Porto, 2006. MARX, Karl. Capital Vol I, Chapter xxvi, Progress Publishers, Moscow, 669 MATEUS, Dalila Cabrita. "El Trabajo Forzado en las Colonias Portuguesas" in Historia,

5 Célebre frase proferida por Salazar em discurso público a 13 de Abril de 1961, que marca o início da guerra colonial em Angola. 
Issn: 1808 - 799X

ano 14, número $24-2016$

Trabajo y Sociedad, no 4, 2013, 63-87

PEREIRA, Rui M.. "Raça, Sangue e Robustez. Os paradigmas da Antropologia Física Colonial Portuguesa", Cadernos de Estudos Africanos (Online), 7/8 2005, posto online no dia 03 de Junho 2014, consultado o 22 Dezembro 2014. URL : http://cea.revues.org/1363 ; DOI : 10.4000/cea.1363

RIBEIRO, Orlando. A colonização de Angola e o seu fracasso. Imprensa Nacional Casa da Moeda, Lisboa, 1981

RODRIGUES, Sarmento M.M., Caminhos do Futuro nos Horizontes da Nação, Grupo de Estudo e Trabalho, Lourenço Marques, 1962

Recebido: 15 de fevereiro de 2016 Aprovado: 21 de junho de 2016 